\title{
THE USE OF CALCIUM ION NANOSTRUCTURE IMPLANT SYSTEM FOR MISSING MAXILLARY ANTERIOR TEETH
}

\author{
Bassant A. Mohamed ${ }^{1}$ BDS, Saeeda Osman² PhD, Magued H. Fahmy² PhD
}

\begin{abstract}
INTRODUCTION: The goal of modern dentistry is to restore the patient to normal contour, function, comfort, esthetics, speech and health regardless of the atrophy, disease or injury of the stomatognathic system. Dental implant is defined as a prosthetic device alloplastic material implanted into the oral tissues beneath the mucosal or periosteal layer within the bone to provide retention and support for a fixed or removable prosthesis.

OBJECTIVES: The aim of this study was to evaluate clinically and radiographically the use of calcium ion surface treated nanostructure implant system for missing maxillary anterior teeth.

MATERIALS AND METHODS: Eleven patients with anterior maxillary missing tooth were treated with calcium ion nanostructure implant. An implant stability and assessment of the osseointegration progress evaluation was conducted using the resonance frequency analysis technique (Osstell) immediately after implant placement and after one and half month at the loading time. Also, radiographic investigations were performed after one and half and three months to estimate the peri-implant mean bone density.

RESULTS: all of the cases showed an uneventful wound healing. Mean bone density after three months showed a statistically significant $(p<0.001)$ increase in its values when compared to the immediately postoperative values. Implant stability showed statistical significant difference detected clinically by Osstell.
\end{abstract}

CONCLUSIONS: The calcium ion nanostructure implant system showed an adequate clinical and radiographic performance in the replacement of missing maxillary anterior teeth with and early loading protocol.

KEYWORDS: Osstell ISQ, osseointegration, Xpeed.

1. BDS, MS, Oral and Maxillofacial Surgery, Department of Oral and Maxillofacial Surgery, Faculty of Dentistry, Alexandria University, Egypt.

2. Professor of Oral and Maxillofacial Surgery, Department of Oral and Maxillofacial Surgery, Faculty of Dentistry, Alexandria University, Egypt.

Corresponding author:

E-mail: bassantahmed188@gmail.com

\section{INTRODUCTION}

Dental Implantology, a special field of dentistry dealing with the rehabilitation of the damaged chewing apparatus due to loss of the natural teeth, is currently the most intensively developing field of dentistry. Missing teeth can be replaced using dental implants (artificial roots), which are inserted into root bearing parts of the mandible or maxilla. The success and long-term prognosis of implant prosthetic therapy depend primarily on the anchorage of the implant in the jaw bone (1). Brånemark et al (2) classified dental implants depending on the anatomical relation of the implant to the surrounding tissue into Intra mucosal or Mucosal Insert.

In the early 1960s Branemark and co-workers (3) started developing a novel implant system for clinical function depended on direct bone anchorage termed osseointegration. Osseo-integration is defined as a firm direct structural and functional connection between vital bone and the surface of load bearing implant at the light microscopic level (4). High success rates were seen with long-term results of using osseointegrated implants (5).

Implant stability is determined by the measurement of clinical implant immobility which is an indirect osseointegration indicator and a prerequisite for the longterm clinical success of osseointegrated implants $(6,7)$. Local bone quality and quantity, geometry of an implant, and the placement technique used affect the primary implant stability. Secondary stability depends mainly on primary stability, bone remodeling and implant surface condition
$(8,9)$. Secondary stability has been shown to begin to increase at 4 weeks after implant placement. At this time, the lowest implant stability is expected (6).

Resonance frequency analysis is a bending test of the implant-bone complex helping to objectively and noninvasively determine implant stability and to assess the progress of osseointegration, without jeopardizing the healing process. This analysis is commercially available as: Osstell (Integration Diagnostics) and Implomates (Bio Tech One). $(6,10)$ Resonance frequency values ranging from 3,500 to $8,500 \mathrm{~Hz}$ are translated into an ISQ of 0 to 100 . A high value indicates greater stability, whereas a low value implies instability. The manufacturer's guidelines suggest that successful implant typically has an ISQ greater than 65 (11).

When an oral implant is inserted into the bone, stem cells initially adhere to the implant surface which in turn plays an importance role in facilitating differentiation of cells along the osteoblast line to improve osseointegration (12). Thus, a rapidly established, strong and long lasting bond at the implant-bone interface is essential for the successful clinical application of oral implants (13). This primarily depends on the characteristics of the implant surface.

Implant surface treatment is performed in an attempt to improve the biomechanical properties of the implant such as stimulation of bone formation to enhance osseointegration, removal of surface contaminants, and improvement of wear and corrosion resistance (14). 
Mechanical, chemical, and physical surface modifications can be employed to change the implant surface chemistry, morphology, and structure (14).

The Xpeed is a unique surface treatment based on Sandblasting and acid etching (SLA) technique with calcium ion incorporation process. Calcium ion creates a CaTiO3 nanostructure on the surface which activates and increases the growth of osteoblasts in the living organisms, (15) therefore accelerating the osseointegration process at both cellular and histological levels (16-18). It also promotes the precipitation of apatite on the titanium surfaces forming a nano-thickness layer which do not peel nor absorbed after fixture placement which in contrast to the conventional hydroxyapatite coating $(19,20)$.

Recently, nanostructure calcium coating on titanium designs have become of particular interest due to their favorable function, (21) reporting a large degree of effectiveness in many in vitro and in vivo studies (15).

Therefore, the aim of this study was to evaluate clinically and radiographically the use of calcium ion surface treated nanostructure implant system for missing maxillary anterior teeth.

\section{MATERIALS AND METHODS \\ Informed Consent}

The ethical committee approval was obtained before the study began, and the selected patients were being informed about the nature of the study and signed an informed consent.

\section{Patient selection and evaluation}

This study was a prospective clinical trial conducted on 11 patients requiring 12 implants for missing anterior maxillary teeth. The patients were selected from the outpatient clinic of the Oral and Maxillofacial Surgery Department, Faculty of Dentistry, Alexandria University.

\section{Inclusion criteria}

Patients with adequate oral hygiene and good general health with missing anterior maxillary tooth/teeth were included in this study. Also they were free of soft tissue or oral dental pathology. Confirmed motivation regarding implant treatment was obtained.

\section{Exclusion criteria}

Patients suffering from relevant systemic and/or uncontrolled metabolic diseases, immunosuppressive and/or autoimmune diseases, psychological disease or suspected psychological disorder, and those with any general contraindications for implant surgery were excluded. Also, heavy smokers and those burdened with parafunctional habits such as bruxism or clenching were ineligible for enrollment in this study. Furthermore, patients with poor oral hygiene or low motivation were excluded.

\section{MATERIALS}

\section{1- Implants}

Megagen Any ridge ${ }^{\circledR}$ (Megagen Implants, UK) is an implant with a unique XPEED ${ }^{\circledR}$ surface treatment based on Sandblasted Large Grid Acid Etch (S-L-A) technique with nano layer of calcium incorporated.

\section{2- Implant Stability Quotient (ISQ) monitor}

The resonance frequency analysis technique was used to objectively and non-invasively determine implant stability and to assess the progress of osseointegration using Osstell ISQ monitor (Stampgatan, Gothenburg, Sweden) and a standardized abutment Smartpeg.

\section{METHODS}

\section{Preoperative phase}

Prior to any treatment approach, every patient was thoroughly evaluated regarding both dental and medical status. Patients' data was collected and recorded in full details, including name, age, gender, occupation, address, telephone number, medical and dental history. The oral mucosa of the edentulous area was examined for color, texture, firmness and thickness. A thorough preoperative radiographic examination was conducted using cone beam computerized tomography (CBCT) to verify the residual ridge height and width implant position, angulations, and depth (Figure 1). A surgical guide stent was constructed for each patient using a preoperative diagnostic cast and a mock wax-up.

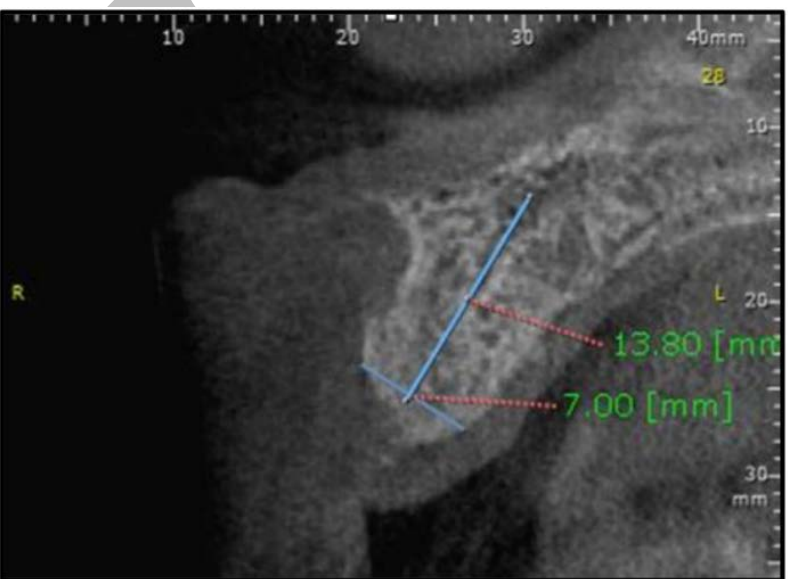

Figure 1:A photograph showing preoperative CBCT showing missing maxillary right central.

\section{Surgical procedure}

Before surgery, an antiseptic mouthwash chlorhexidine solution (Hexitol, the Arab Drug Company, Cairo, A.R.E.) was applied as prophylaxis and the fabricated surgical stent was checked for proper seating. All patients were operated under local anesthesia using maxillary vestibular and palatal infiltration in the implant- drilling site using articaine hydrochloride 4\% and levonordefrin 1:100,000 (Septocaine, Septodont, USA). A Full thickness crestal incision was performed by blade number 15 followed by mucoperiosteal flap gentle reflection. The drilling of the implant site followed the principles and guidelines of the Megagen Any ridge ${ }^{\circledR}$ system. The initiating drill points of implant was begun guided by the stent using $1.8 \mathrm{~mm}$ drill pit (piolet drill), followed by the sequence of drills according to the chosen implant diameter.

The implant was then placed in the bone (Figure 2). The Smartpeg was secured into the implant and the transducer probe was held so that the probe tip was aimed at the small magnet on top of the standardized abutment at a distance of 2-3mm, and the immediate Implant Stability Quotient (ISQ) value was determined (Figure 3 ). The SmartpegTM was removed and a cover screw was placed, followed by wound Closure using 3-0 silk suture material.

\section{Postoperative phase}

All patients were instructed to apply intermittent cold fomentation starting immediately postoperatively and avoid hot food on the first day. Chlorhexidine mouth rinse was started on the 2nd post-operative day 3 times daily for 10 weeks. Patients were advised to follow proper oral hygiene instruction and to utilize a soft high nutrient diet. Sutures were removed one week after surgery. Postoperative 
administration of a broad spectrum antibiotic Amoxicillin 875 mg + Clavulanic acid 125 mg tablets (Augmentin 1 gm SmitKhline Beecham Pharmaceutical Co., Bentford, England) every 12 hours for 7 days to avoid post-operative infection. Non-steroidal anti-inflammatory analgesic in the form of diclofenac potassium $50 \mathrm{mg}$ tablets (Cataflam 50 mg tablets, Novartis Pharma AG, Basle, Switzerland) every 8 hours for 7-10 days to avoid the possibility of inflammation, edema and pain.

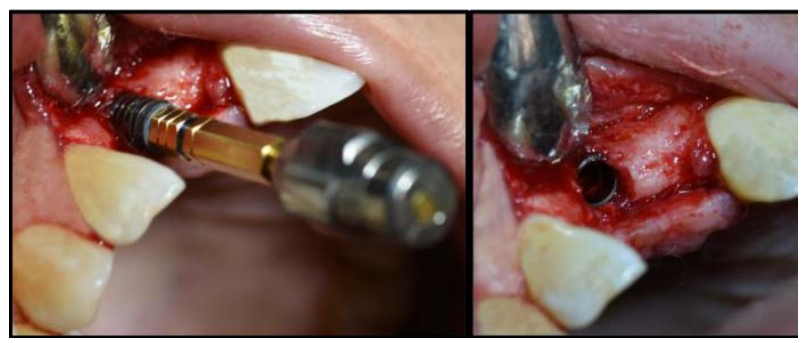

Figure 2: A photograph showing the placement of the implant.

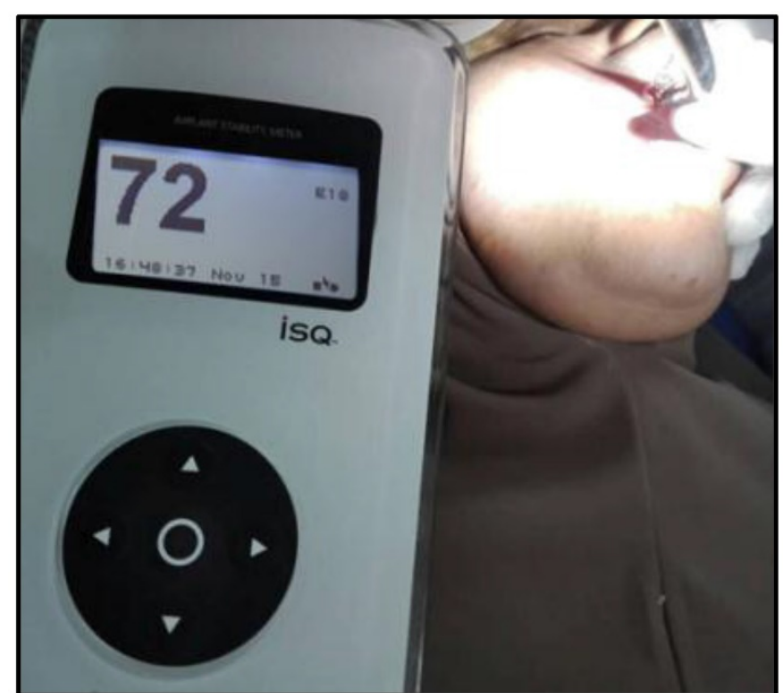

Figure 3: A photograph showing the Ostell reading (primary stability).

\section{Follow up phase}

A thorough Follow-up was performed for the assessment of the clinical parameters of importance for the determination of implant success which included: Absence of pain, edema, wound dehiscence, implant mobility or any other complications related to implant placement. Pain was examined using visual analogue scale (VAS) daily in the first postoperative week, where a zero value regarded to be pain free and the most severe pain was rated at 10 .

Edema was evaluated the day after the surgery and after the first week by its ability to pit according to visual descriptor scale (VDS) where it was graded on a scale of +1 (slight indentation) to +4 (8mm indentation). The sutured wounds were examined for signs and symptoms of infection including swelling, redness, hotness, pus discharge, and pain in addition to observation of any manifestations of wound healing disturbance, as wound dehiscence and hardware exposure.

After one and half month, a second stage surgery to remove the cover screw was performed. Implant stability quotient values were measured via the Osstell system using the Smartpeg and the attained value was compared to the baseline reading at the time of the surgery (Figure 4).

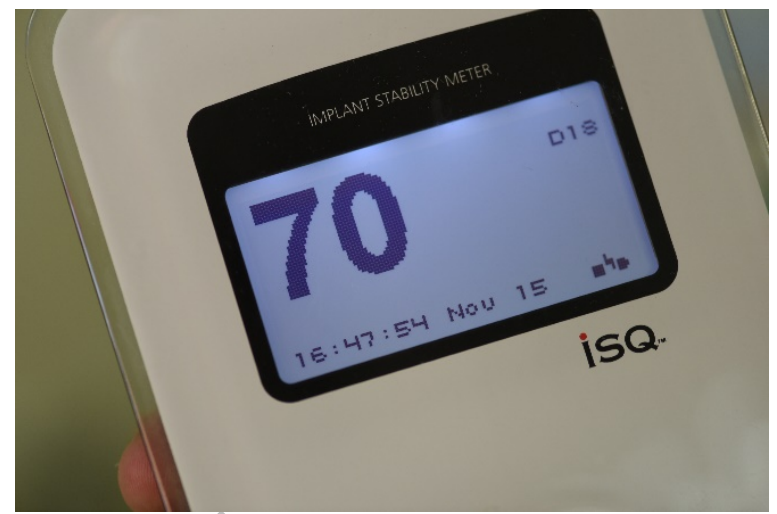

Figure 4: A photograph showing Ostell reading after one and half month (secondary stability).

Cone beam computerized tomography was obtained after one and half and 3 months (Figure 5) to assess bone density and the formation of bone around implant. CBCT measurements were performed using OnDemand3D ${ }^{\mathrm{TM}} \mathrm{App}-$ DBM software system (Cybernet, Korea) where the bone density was calculated directly in Hounsfield Unit (HU).

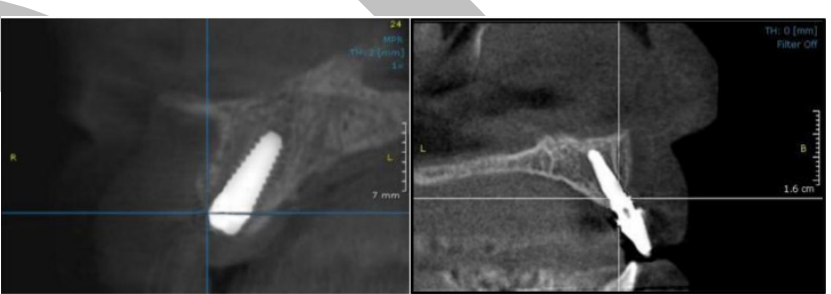

Figure 5:(A) A photograph showing one and half postoperative CBCT of implant placed at the maxillary right central area.

(B) A photograph showing three months postoperative CBCT of implant placed at the maxillary right central area.

\section{Prosthetic phase}

The loading time was set at one and half postoperative month, where definitive porcelain fused to metal restorations were delivered to all patients (Figure 6).

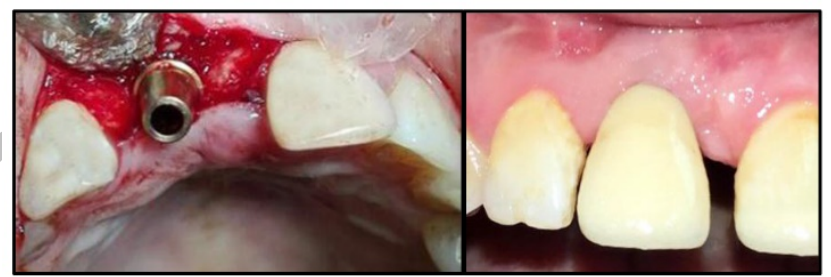

Figure 6: A photograph showing the abutment in place.

\section{Statistical analysis}

Data were fed to the computer and analyzed using IBM SPSS software package version 20.0. (Armonk, NY: IBM Corp). Quantitative data were described using range, mean, standard deviation and median. The distribution of quantitative variables was tested for normality using Kolmogorov-Smirnov test. The paired t- test was used to compare between two periods showing normally distributed quantitative variables, while the ANOVA with repeated measures was used to compare between more than two periods or stages, and Bonferroni Post Hoc test. The Friedman test was used for abnormally distributed quantitative variables, with Dunn's Post Hoc Test. Significance of the obtained results was judged at the $5 \%$ level. 


\section{RESULTS}

A total of twelve implants were placed in eleven patients of ages ( 25 - 50) years with a mean age of $(34.33 \pm 8.76)$ years, they were of both sexes (4 males and 7 females). In this study, eleven patients needed single implants. While, one patient needed two implants. All patients were followed up for 3 months and results were registered as regards to clinical and radiographic evaluation.

\section{Clinical results}

After surgery, five patients experienced mild pain (VAS=24 ), and three patients experienced moderate pain (VAS $=5$ 7) at surgical site that lasted for 1-3 days. Four patients suffered from trace edema (VDS $=+1$ ), which subsided totally by the second post-operative day, while two patients suffered from mild edema which lasted for 4 days (VDS= +2 ). All patients continued the follow-up period without signs of infection.

All of the implants showed Osstell readings higher than 65 and loading was performed after one and half month. The mean implant stability quotient at day of surgery was $73.83 \pm 3.61$. There was a decrease after one and half month $72.33 \pm 3.28$. The difference in implant stability between the two time of periods was found to be statistically significant $(\mathrm{P}=0.007)$. (Table 1$)$

Table 1: Comparison between the two studied periods according to ostell $(n=12)$

\begin{tabular}{||c|c|c|c|c||}
\hline & Immediately & $\begin{array}{c}\text { After one } \\
\text { and half } \\
\text { month }\end{array}$ & t & p \\
\hline $\begin{array}{c}\text { Min. }- \\
\text { Ostel } \\
\text { Mean. } \\
\text { SD. } \\
\text { Median }\end{array}$ & $69.0-80.0$ & $68.0-78.0$ & & \\
\hline Diff. Ch. & $7.61 \pm 73.83$ & $3.28 \pm 72.33$ & $\underset{*}{3.317}$ & $\begin{array}{c}0.007 \\
*\end{array}$ \\
\hline \% of Ch. & \multicolumn{2}{|c|}{$\downarrow 1.50 \pm 1.57$} & 71.50 & \\
\hline
\end{tabular}

t: $t$ for Paired t-test

$\mathrm{p}$ : $\mathrm{p}$ value for comparing between the two periods

*: Statistically significant at $\mathrm{p} \leq 0.05$

\section{Radiographic results}

The mean bone density was calculated by measuring bone density using CBCT to determine the preoperative, one and half month postoperative and 3 months postoperative mean bone density. All of the measurements were in Hounsfield Units (HU). Preoperatively, the mean peri-implant bone density value was $1187.7 \pm 240.1 \mathrm{HU}$, while the mean periimplant bone density one and half month postoperatively for the same area was $1377.5 \pm 347.0 \mathrm{HU}$, and at three postoperative months was1620.3 $\pm 261.1 \mathrm{HU}$. The difference in bone densities between the three periods was found to be statistically significant $\mathrm{P}<0.001 *$. (Table 2)
Table (2): Comparison between the three studied periods according to bone density (average)

\begin{tabular}{|c|c|c|c|c|c|}
\hline $\begin{array}{c}\text { Bone } \\
\text { Density }\end{array}$ & $\begin{array}{l}\text { Preope } \\
\text { rative }\end{array}$ & $\begin{array}{c}\begin{array}{c}\text { One and } \\
\text { half } \\
\text { month }\end{array} \\
\end{array}$ & 3 month & $\mathbf{F}$ & $\mathbf{p}$ \\
\hline Average & & & & & \\
\hline Min & & & & & \\
\hline . - & 818.0 - & $633.3-$ & $1259.0-$ & & \\
\hline $\operatorname{Max}$ & 1598.4 & 1836.7 & 2067.7 & & \\
\hline Mea & 11877 & +13775 & +16203 & $\underset{*}{26.892}$ & $<0.00$ \\
\hline $\begin{array}{c}\mathrm{n} \pm \\
\mathrm{SD}\end{array}$ & $240.1 \pm$ & 347.0 & 261.1 & & \\
\hline $\begin{array}{r}\text { Med } \\
\text { ian }\end{array}$ & 1157.5 & 1421.6 & 1534.6 & & \\
\hline $\begin{array}{l}\text { Sig. bet. } \\
\text { periods. }\end{array}$ & \multicolumn{3}{|c|}{$\mathrm{p}_{1}=0.038^{*}, \mathrm{p}_{2}<0.001^{*}, \mathrm{p}_{3}=0.008^{*}$} & & \\
\hline $\begin{array}{l}\text { \% of } \\
\text { Ch. }\end{array}$ & \multicolumn{3}{|c|}{$\begin{array}{c}\mathrm{Ch}_{1}=7.3 \pm 12.3, \mathrm{Ch}_{2}=15.3 \pm 15.3 \\
\mathrm{Ch}_{3}=7.6 \pm 9.0\end{array}$} & & \\
\hline $\begin{array}{l}\text { Diff. } \\
\text { Ch. }\end{array}$ & \multicolumn{3}{|c|}{$\begin{array}{c}\mathrm{Ch}_{1}=189.8 \pm 221.6, \mathrm{Ch}_{2}=432.6 \pm \\
171.7, \mathrm{Ch}_{3}=242.8 \pm 217.5\end{array}$} & & \\
\hline
\end{tabular}

F: F test (ANOVA) with repeated measures, Sig. bet. periods was done using Post Hoc Test (Bonferroni)

$\mathrm{p}$ : $\mathrm{p}$ value for comparison between different periods

p1: $p$ value for comparing between preoperative and one and half month

p2: $p$ value for comparing between preoperative and 3month

p3: $p$ value for comparing between one and half month and 3 month

$*$ : Statistically significant at $\mathrm{p} \leq 0.05$

$\mathrm{Ch}_{1}$ : \% of change from preoperative to one and half month

$\mathrm{Ch}_{2}$ : \% of change from preoperative to 3 months

$\mathrm{Ch}_{3}$ : \% of change from one and half month to 3 months

\section{DISCUSSION}

Dental implant therapy is one of the pioneering treatment modality for replacement of missing teeth. It is well understood that, patients are more satisfied with implant supported prosthetic rehabilitation in terms of comfort, stability and esthetics compared to conventional prosthesis.

This present study was conducted on 11 patients in need for implant placement for their lost anterior maxillary teeth with the aim to evaluate the clinical and radiographic bone response to implants with nanostructure calcium incorporated as a surface treatment. It was decided to evaluate only the maxilla in the present study since sites characterized by softer bone are more commonly encountered, which may put the implants at a higher risk for implant failures. The hypothesis behind this choice was that the potential clinical advantages of an improved bone-toimplant contact observed in animal studies around calciumincorporated implants over control implants could be more easily observed in maxillae (22).

Patient's general condition was emphasized not to add confounding factor that may affect the outcome of the study. All patients were non-smokers. In 2014, Clementini et al (23) concluded that exposure to smoking has a harmful effect on the peri-implant bone loss that eventually lead to implant failure. Also, all patients were selected free from systemic diseases because that may complicate the surgical procedure or the healing process of the implant procedure as advocated by Bolender in 1988 (24) and Dhanrajani and Al-Rafee in 2005 (25). Selected patients were also free from parafunctional habits such as bruxism and clenching. In such patients, the duration of the forces is extensive and their direction is more horizontal than axial to the implants, which leads to mechanical complications and failure of implants according to Manfredini et al in 2014 (26). 
Resonance Frequency Analysis (RFA) is a noninvasive intraoral method designed to assess bone-implant interface and may therefore provide an objective clinical assessment of implant stability. RFA allows implant monitoring through sequential stability measurements, as well as indirect assessment of the influence of osseous remodeling around the implant on secondary implant stability. The utilized RFA device (Osstell) reading lacks reproducibility that's why several registers are recorded and the mean value is the one taken in consideration in order to increase the ISQ results reliability (27).

RFA registrations are directly related to the stiffness of the implant in the surrounding bone: during healing an increase in implant stability quotient (ISQ) values presumably reflect new bone apposition at the implant-bone interface (28).

In 1996 and 1997, Meredith et al $(28,29)$ supporting this review when stated that RFA can serve as a useful research technique and may prove to be valuable in studying the behavior of implants in surrounding tissue. In this study a non-contacting method was used allowing the testing of the implant stability from any surface in $360^{\circ}$ around the implant fixture.

In this study an early loading protocol was mandate as all implants recorded higher than 65 after six months, so that the secondary stage surgery was performed

This result is in accordance with the outcome reached by the majority of studies that investigated osseointegration and implant stability at or before fourth postoperative week with the need for an early loading scheme (30-32). It is agreed upon in the literature that during the first two months following implantation, a bone remodeling with partial loss of initial mechanical stabilization of the implant occurs $(33,34)$. The higher values at the day of the operation represents the primary implant stability which is the result of the proper initial contact between the implant surface and the preexisting alveolar bone $(6,7,35)$.

A secondary stabilization (osseointegration) will be attained if this encountered remodeling is effectively counteracted and balanced by an adequate and rapid deposition of new bone on the implant surface $(33,34)$. However, to asses this secondary stability using RFA requires a regular, not early, loading protocol as it begins to increase two months after implant placement (6).

The encountered significant decrease in the ISQ records, despite not being below the 65 threshold, may clarify that at the early loading time (six weeks) the effect of the calcium nano layer will not be emphasized. This outcome was reached by Li et al in 2015 (18) where they conducted a randomized clinical trial and compared titanium with calcium nano layer on its surface with untreated titanium surfaces, and no significant difference was encountered at the fourth postoperative week. However, a significant difference was recorded at the twelfth week, where the mean ISQ value was higher than that at the time of implantation and higher than the control group.

Regarding the postoperative radiographic assessment, various imaging options are available for the evaluation of the recipient site. In the present study, CBCT was taken for each patient. CBCT was taken preoperatively, one and half month, and on the third postoperative month to detect the changes in bone density surrounding dental implants. According to the studies conducted by Cassetta et al in 2013 (36) and Bornstein et al in 2014 (37), they reported that the use of CBCT in implant dentistry vary from preoperative analysis regarding specific anatomic considerations and treatment planning to postoperative evaluation. Along with, lower radiation dose reduced costs and the relative grey density values of CBCT images making it a useful substitute for computerized tomography (CT) (38).

The mean preoperative peri-implant bone density value was $1187.7 \pm 240.1 \mathrm{HU}$, while that at the loading time was $1377.5 \pm 347.0 \mathrm{HU}$. This increase in bone density was statistically significant $(\mathrm{P}=0.038)$. The three months postoperative scan revealed an increase in the recorded mean bone density, where it scored a 1620.3 $\pm 261.1 \mathrm{HU}$. Once again the difference between the three months' record and the one at the loading time was statistically significant $(\mathrm{P}=0.008)$. The increase in the mean peri-implant bone density across the follow up period was statistically significant $(\mathrm{P}<0.001)$.

These results are in accordance with those reached by $\mathrm{Li}$ et al in 2015 (18), where a statistically significant increase in the mean peri-implant bone density at the twelve week records when compared to the immediate postoperative once was found.

In 2015, Cheng et al (13) found that coating the implant surface with calcium caused the bone surrounding the titanium surface to increase along with the implantation time. Also more bone was found than in non-calcium treated implant surface. Cheng et al (13) also stated a significantly higher bone-implant contact value for $\mathrm{Ca}-\mathrm{SLA}$-Titanium implants.

It is reasonable to believe that the incorporation of $\mathrm{Ca}$ ions on the rough surface can improve the in vivo osseointegration, this may have contributed to the unique surface treatment of the utilized implants. The CaTIO3 nanostructure coating on titanium surface simulate the organic and inorganic components of natural bone tissue, which guides bone formation along the bone-implant interface. This CaTIO3 coating also enhances apatite precipitation on the titanium surface creating nano layer which tends to persevere after fixture placement $(19,20)$. The early bone response to implants is critical for the degree of bone to implant contact and subsequently for implant fixation, which may be explained by the early stimulation of bone healing at the implant interface by the applied $\mathrm{Ca}$ ions.

Furthermore, the increase in bone density after loading may point out the potential of the nano calcium layer in the enhancement of the secondary stability even after early fixture loading. This might be clinically useful for lower bone quality and in patients with compromised bone conditions such as osteoporosis or inadequate bone height (20).

Implant surface topography and element composition regulates the process of bone formation, which consists of cell adhesion, spread, proliferation, differentiation and mineralization. The importance of the SLA for the calcium layer is for the enhancement of osteoconductivity of the implant surface which might increase the reactivity of the calcium nano-layer by enlarging its surface area exposed to the biological environment (27).

However, it is debated whether surface roughness alone can induce osseointegration through osteoblastic differentiation. Anselme et al in 2005 (39) declared that cell adhesion and proliferation decreased with increasing material surface roughness. The introduction of the calcium 
ions on the surface of SLA-Titanium showed promising results in regard to osteoblastic differentiation, cell adhesion, spread and proliferation $(19,20)$. Nayab et al in 2005 (40) claimed that Osteoblasts grown on $\mathrm{Ca}-$ SLA-Titanium surfaces exhibited significantly better cell adhesion, spread and proliferation than that of cells on SLA-Titanium surfaces.

These conclusions are well demonstrated in this study by the favorable clinical and radiographic outcomes despite the limitations in the study as it lacks a comparison group and a longer follow up period may be recommended. Furthermore, the concept of early loading may require further comparison with normal loading protocols which will enable further testing for the secondary stability of the implant.

To sum up, implants with calcium ion surface treated nanostructure showed an adequate clinical and radiographic performance in the replacement of missing maxillary anterior teeth with and early loading protocol.

\section{CONCLUSION}

From the results of this study we can conclude that replacing missing maxillary anterior teeth with calcium ion surface treated nanostructure showed an adequate clinical and radiographic performance with an early loading protocol

\section{CONFLICT OF INTEREST}

The authors declare that they have no conflicts of interest.

\section{REFERENCES}

1- Adell R, Eriksson B, Lekholm U, Branemark PI. Longterm follow-up study of osseointegrated implants in the treatment of totally edentulous jaws. Int J Oral Maxillofac Implants. 1990;5:347-59.

2- Adell R Lekholm U, Rockler B, Branemark PI. A 15 year study of osseointegrated implants in the treatment of the edentoulous jaw. Int J Oral Surg. 1981;10:387-416.

3- Branemark PI, Adell R, Breine U, Hansson BO, Lindstrom J. Intra-osseous anchorage of dental prostheses. I. Experimental studies. Scand J Plast Reconstr Surg. 1969;3:81-100.

4- Albrektsson T, Branemark PI, Hansson HA, Lindstrom J. Osseointegrated titanium implants. Requirements for ensuring a long-lasting, direct bone-to-implant anchorage in man. Acta Orthop Scand. 1981;52:155-70.

5- Adell R, Lekholm U, Rockler B, Branemark PI. A 15year study of osseointegrated implants in the treatment of the edentulous jaw. Int J Oral Surg. 1981;10:387-416.

6- Atsumi M, Park SH, Wang HL. Methods used to assess implant stability: current status. Int J Oral Maxillofac Implants. 2007;22:743-54.

7- Meredith N, Alleyne D, Cawley P. Quantitative determination of the stability of the implant-tissue interface using resonance frequency analysis. Clin Oral Implants Res. 1996;7:261-7.

8- Zix J, Hugs, Kessler-Liechti G, Mericske-Stern R. Measurement of dental implant stability by resonance frequency analysis and damping capacity assessment: comparison of both techniques in a clinical trial. Int J Oral Maxillofac Implants. 2008;23:525-30.

9- Sim CP, Lang NP. Factors influencing resonance frequency analysis assessed by osstell mentor during implant tissue integration: I. Instrument positioning, bone structure, implant length. Clin Oral Implants Res. 2010;21:598-604.

10- Van der perre G, Lowet G. Vibration, sonic and ultrasonic wave propagation analysis for the detection of osteoporosis. Clin Rheumatol. 1994;13:45-5.

11- Veltri M, Balleri P, Ferrari M. Influence of transducer orientation on Osstell stability measurements of osseointegrated implants. Clin Implant Dent Relat Res. 2007;9:60-4.

12- Mendonça G, Mendonça DB, Aragão FJ, Cooper LF. Advancing dental implant surface technology--from micron- to nanotopography. Biomaterials. 2008;29:382235.

13- Cheng M, Qiao Y, Wang Q, Jin G, Qin H, Zhao Y, et al. Calcium plasma implanted titanium surface with hierarchical microstructure for improving the bone formation. ACS Appl Mater Interfaces. 2015;7:13053-61.

14- Wennerberg A, Albrektsson T. Effects of titanium surface topography on bone integration: a systematic review. Clin Oral Implants Res. 2009;20(Suppl 4):172-84.

15- Nayab SN, Jones FH, Olsen I. Effects of calcium ion implantation on human bone cell interaction with titanium. Biomaterials. 2005;26:4717-27.

16- Ribeiro AR, Oliveira F, Boldrini LC, Leite PE, FalaganLotsch P, Linhares AB, et al. Micro-arc oxidation as a tool to develop multifunctional calcium-rich surfaces for dental implant applications. Mater Sci Eng C Mater Biol Appl. 2015;54:196-206.

17- Huang Q, Liu X, Elkhooly TA, Zhang R, Shen Z, Feng Q. A novel titania/calcium silicate hydrate hierarchical coating on titanium. Colloids Surf B Biointerfaces. 2015;134:169-77.

18- Li JY, Pow EHN, Zheng LW, Ma L, Kwong DLW, Cheung LK. Effects of calcium phosphate nanocrystals on osseointegration of titanium implant in irradiated bone. Biomed Res Int. 2015;2015:783894.

19- Webster TJ, Ergun C, Doremus RH, Lanford WA. Increased osteoblast adhesion on titanium-coated hydroxylapatite that forms CaTiO3. J Biomed Mater Res Part A. 2003;67:975-80.

20- Conserva E, Consolo U. Biological cell activity and gene expression on implants with different macro/micro structured surfaces and chemical composition. Conference: Conference: Mega Gen European Scientific Meeting; 2013.

21- Zhang W, Li Z, Liu Y, Ye D, Li J, Xu L, et al. Biofunctionalization of a titanium surface with a nanosawtooth structure regulates the behavior of rat bone marrow mesenchymal stem cells. Int J Nanomedicine. 2012;7:4459-72. 
22- Lee SY, Yang DJ, Yeo S, An HW, Kim SJ, Choi WM, et al. Effect of XPEED® on Ti implants with deep threads. Key Eng Mater. 2012;493:442-6.

23- Clementini M, Rossetti P, Penarrocha D, Micarelli C, Bonachela W, Canullo L. Systemic risk factors for periimplant bone loss: a systematic review and meta-analysis. Int J Oral Maxillofac Surg. 2014;43:323-34.

24- Bolender CL. Indications and contraindications for different types of implant therapy. J Dent Educ. 1988;52:757-9.

25- Dhanrajani PJ, Al-Rafee MA. Single-tooth implant restorations: a retrospective study. Implant Dent. 2005;14:125-30.

26- Manfredini D, Poggio CE, Lobbezoo F. Is bruxism a risk factor for dental implants? A systematic review of the literature. Clin Implant Dent Relat Res. 2014;16:460-9.

27- Nebe JB, Muller L, Luthen F, Ewald A, Bergemann C, Conforto E, et al. Osteoblast response to biomimetically altered titanium surfaces. Acta Biomater. 2008;4:198595.

28- Meredith N, Books K, Fribergs B, Jemt T, Sennerby L. Resonance frequency measurements of implant stability in viva. A cross-sectional and longitudinal study of resonance frequency measurements on implants in the edentulous and partially dentate maxilla. Clin Oral Implants Res. 1997;8:226-33.

29- Meredith N, Alleyne D, Cawley P. Quantitative determination of the stability of the implant-tissue interface using resonance frequency analysis. Clin Oral Implants Res. 1996;7:261-7.

30- Chappuis V, Araújo MG, Buser D. Clinical relevance of dimensional bone and soft tissue alterations postextraction in esthetic sites. Periodontol 2000. 2017;73:73-83.

31- Stanley M, Braga FC, Jordao BM. Immediate loading of single implants in the anterior maxilla: A 1-year prospective clinical study on 34 patients. Int J Dent. 2017;2017:8346496.

32- Mangano FG, Mastrangelo P, Luongo F, Blay A, Tunchel S, Mangano C. Aesthetic outcome of immediately restored single implants placed in extraction sockets and healed sites of the anterior maxilla: a retrospective study on 103 patients with 3 years of follow-up. Clin Oral Implants Res. 2017;28:272-82.

33- Schouten C, Meijer GJ, van den Beucken JJJP, Spauwen PHM, Jansen JA. The quantitative assessment of periimplant bone responses using histomorphometry and micro-computed tomography. Biomaterials. 2009;30:4539-49.

34- Xie C, Lu H, Li W, Chen F-M, Zhao Y-M. The use of calcium phosphate-based biomaterials in implant dentistry. J Mater Sci Mater Med. 2012;23:853-62.

35- Heller JG, Bradley T, Estes MS, Diop A. Biomechanical study of screws in the lateral masses: variables affecting pull-out resistance. J Bone Joint Surg AM. 1996;78:131521.
36- Cassetta M, Sofan AA, Altieri F, Barbato E. Evaluation of alveolar cortical bone thickness and density for orthodontic mini-implant placement. J Clin Exp Dent. 2013;5:e245-52.

37- Bornstein MM, Scarfe WC, Vaughn VM, Jacobs R. Cone beam computed tomography in implant dentistry: a systematic review focusing on guidelines, indications, and radiation dose risks. Int J Oral Maxillofac Implants. 2014;29(Suppl):55-77.

38- Chasioti E, Sayed M, Drew H. Novel techniques with the aid of a staged CBCT guided surgical protocol. Case Rep Dent. 2015;2015:439706.

39- Anselme K, Bigerelle M. Topography Effects of Pure Titanium Substrates on Human Osteoblast Long-Term Adhesion. Acta Biomater. 2005;1:211-22.

40- Nayab SN, Jones FH, Olsen I. Effects of Calcium IonImplantation of Titanium on Bone Cell Function in Vitro. J Biomed Mater Res Part A. 2007;83:296-302. 